\title{
Habitat-specific vegetation and seasonal drivers of bird community structure and function in southern Patagonian forests
}

\author{
G. M. Pastur ${ }^{1}$, M. V. Lencinas¹, E. Gallo², M. de Cruz³, M. L. Borla ${ }^{3}$, R. S. Esteban ${ }^{1}$ \\ and C. B. Anderson $1,4,5$ \\ ${ }^{1}$ Laboratorio de Recursos Agro-Forestales, Centro Austral de Investigaciones Cientificas (CADIC-CONICET), Houssay \\ 200 (9410) Ushuaia, Tierra del Fuego, Argentina \\ 2 Parque Nacional Tierra del Fuego (APN), Ushuaia, Tierra del Fuego, Argentina \\ ${ }^{3}$ Magellanic Nature Tours, Ushuaia, Tierra del Fuego, Argentina \\ ${ }^{4}$ Instituto de Ciencias Polares, Ambiente y Recursos Naturales, Universidad Nacional de Tierra del Fuego, Ushuaia, \\ Tierra del Fuego, Argentina \\ ${ }^{5}$ Corresponding author. E-mail: canderson@alumni.unc.edu
}

Keywords: Diversity, Nothofagus, Tierra del Fuego National Park, Trophic ecology, Sub-Antarctic forests.

\begin{abstract}
Biodiversity conservation requires knowledge about the factors that influence the structure and function of biotic assemblages. In southern Patagonian Nothofagus forests, birds are the most abundant and diverse vertebrates and are known to have different requirements for nesting, breeding and feeding. Therefore, we chose this group to analyze key drivers of avian community dynamics; for conservation purposes, this information is requisite to manage Nothofagus forest landscapes and their associated biota. We first characterized forest structure and understory floristic composition in open and closed canopy broadleaved forests of mixed deciduous (MD) and mixed deciduous-evergreen (MDE) species on the southern coast of Tierra del Fuego National Park, Argentina. For each habitat, bird assemblages were assessed using point counts, checklists and mistnetting. We used ANOVAs and multivariate methods to analyze changes in bird species richness, density, and biomass as a function of habitat and seasonal characteristics. Forest structure and understory plant communities influenced avian assemblage and density; MDE forests had significantly greater species richness, but lower density than MD. Plus, particular species were associated with specific understory conditions, such as Anairetes parulus and Zonotrichia capensis whose presence was related to shrubs. Additionally, variations observed between seasons apparently were related to differential uses of each habitat type during certain times of year. Finally, it was not possible to define a single forest type with greater conservation value for birds; each had a specific bird species assemblage. Consequently, our results suggest the importance of a full representation of habitats to preserve the region's bird diversity, which also has been described for forest invertebrates and understory plants.
\end{abstract}

Abbreviations: BA-Total Basal Area, CAR-Carnivore, CC-Canopy Cover, CCA-Canonical Correspondence Analysis, CL-Closed, D-Density, DCA-Detrended Correspondence Analysis, DH-Dominant Height, HER-Herbivore, INS-Insectivore, LAI-Leaf Area Index, MD-Mixed of Deciduous species, MDE-Mixed of Deciduous and Evergreen species, QMD-Quadratic Mean Diameter.

Nomenclature: Clements (2008)

\section{Introduction}

Historically, most regional biodiversity conservation strategies in southern Patagonia have been developed under the aegis of diplomatic initiatives between Chile and Argentina, rather than taking into account specific conservation strategies determined by species- and habitat-specific needs. One result of these politically-driven, rather than scientifically-informed, efforts is that most national parks in southern Patagonia were established along the borders between these two countries. Consequently, Patagonian protected areas are dominated by one forest type, Nothofagus pumilio forest, which is known to host relatively low bird species richness (Lencinas et al. 2005, 2009, Luque et al. 2010), and therefore, the current system of protected areas alone may not fully encompass the region's avian diversity.
In southern Patagonian Nothofagus forests, as in many other forested ecosystems, birds constitute the most abundant and diverse group of vertebrates (Vuilleumier 1985). Birds also are relatively easy to record and to study, and taken together, these conditions make them useful as a general indicator of biodiversity modifications under different scenarios of ecological change, including land use alterations due to forestry management (Deferrari et al. 2001, Lencinas et al. 2005, 2009, Vergara and Schlatter 2006). However, the drivers that affect southern Patagonian bird communities have not been taken into account as part of regional conservation planning, and long-term ecological research has focused instead on community descriptions rather than mechanisms that determine assemblage and distribution (Humphrey et al. 1970, Vuilleumier 1985, Anderson and Rozzi 2000). 
Southern Patagonia's Tierra del Fuego Archipelago consists of a patchy landscape mosaic with several natural forest types intertwined with open habitats in the form of wetlands, peat bogs, shrublands and steppe grasslands (Lencinas et al. 2005,2008 a). Additionally, a history of silvicultural management has produced an anthropogenic matrix of forests with varying degrees of succession and intensity of intervention (Luque et al. 2010, Martínez Pastur et al. 2011). In addition, as the world's southernmost forested biome, these habitats are characterized by having stark seasonal fluctuations in food availability (Becerra Serial and Grigera 2005) and presenting strong spatial/altitudinal resource gradients (Díaz and Kitzberger 2006).

Since Nothofagus forests rarely constitute large, continuous extensions and simultaneously exhibit marked temporal and spatial variability in resources, species occurring only in specific areas acquire greater ecological and conservation importance, while those with less habitat specialization lose relevance for landscape-scale management (Becerra Serial and Grigera 2005, Lencinas et al. 2005, 2009). Therefore, knowledge of species-specific habitat requirements will help in the development of effective conservation strategies, as well as enhance our understanding of migration patterns, regional assemblage dynamics and interactions with other plant and animal species. For these scientific and management reasons, it is necessary to understand which landscape units must be protected as either important or irreplaceable to assure the continuity of resident and migratory bird species (Preseey et al. 2007). Plus, to improve local and regional conservation and management strategies we must also take into account the peninsular and insular nature of southern Patagonia, which can be influenced by island biogeographic processes, historical paleoclimatic or paleogeographic events and recent anthropenic relationships (Battisti 2014).

We chose the forests along the southern coasts of the Argentine portion of Tierra del Fuego Island as a study case to analyze the dynamics of avian community structure (species composition, richness, density) and function (biomass, feeding guild). Specifically, the following questions were addressed: (i) how do bird communities change as a function of forest type and canopy cover? (ii) how do understory plant communities influence the associated avian communities? (iii) how do species and feeding guilds vary between seasons? and (iv) based on the previous answers, is it possible to define forest habitats with outstanding or priority conservation value within the studied landscape? We determined the association of these community factors with habitat variables (forest structure, understory plant composition) and season (spring, summer, autumn, winter). Different bird species are known to have different requirements for nesting, breeding and feeding throughout the year, but seasonal variation in habitat use and community structure has been less studied. At the same time, research elsewhere allows us to hypothesize that two major aspects of habitat vegetation characteristics would affect Fuegian birds: the configuration of vegetation (physiognomy) and the specific species composition (flora) (DeGraaf et al. 1998, Díaz et al. 2005, Lee and Rotenberry 2005, Lindenmayer et al. 2010).

\section{Materials and methods}

\section{Study sites}

The study was conducted in a 1,000 ha site dominated by Nothofagus forests in the southwestern portion of Tierra del Fuego National Park (from 5451'02" S; 68³5'31" W to 5451'27" S; 68³4'12" W). Two habitat types were chosen for avian and vegetation surveys: (i) mixed deciduous (MD) forests, comprised of Nothofagus antarctica and N. pumilio; and (ii) mixed deciduous-evergreen (MDE) forests conformed by deciduous ( $N$. pumilio and N. antarctica) and broad-leaf evergreen species (N. betuloides and Drimys winteri). Both habitat types are found intermixed along the Beagle Channel coast. In each habitat type, we studied two categories of overstory canopy cover: (i) closed canopy with crown cover up to $80 \%$ (CL), and (ii) open canopy areas with crown cover less than $40 \%$ (OP). Three replicates per class were established, obtaining 12 sampling sites ( 2 forest types $\times 2$ canopy cover classes $\times 3$ replicates).

Regional climate of the study area is short, cool summers and long, snowy winters. Only three months per year are free of mean daily air temperatures below $0^{\circ} \mathrm{C}$, and the plant growing season is approximately five months. Rainfall at the study site, including snow, varies from 500 to $1,000 \mathrm{~mm} \mathrm{yr}^{-1}$, depending on altitude and proximity to the sea. Annual average wind speed outside of forests is $8 \mathrm{~km} \mathrm{~h}^{-1}$, reaching up to $100 \mathrm{~km} \mathrm{~h}^{-1}$ during storms (Massaccesi et al. 2008, Martínez Pastur et al. 2011, Kreps et al. 2012).

\section{Forest structure and plant community characterization}

Tierra del Fuego's forested ecosystems are characterized by only three dominant Nothofagus species: $N$. antarctica, $N$. pumilio and $N$. betuloides, which often occur in monospecific stands. At each sampling site, forest structure was characterized in two plots using the point sampling method (Bitterlich 1984) and a Criterion RD-1000 Dendrometer (Laser Technology, USA) with a variable basal area factor (K) between 1 (OP sites) and 6 (CL sites). Forest structure variables were measured in each plot and included dominant tree height (DH), density (D), quadratic mean diameter (QMD) and basal area (BA) (total and discriminated by forest species). To characterize canopy, hemispherical photographs were taken at $1 \mathrm{~m}$ above ground level with an $8 \mathrm{~mm}$ fish eye lens (Sigma, Japan) mounted on a $35 \mathrm{~mm}$ digital camera (Nikon, Japan) with a tripod levelling head to ensure horizontal lens position (for methodologies and user-supplied input variables see Martínez Pastur et al. 2011). Gap Light Analyzer software v.2.0 (Robison and McCarthy 1999, Frazer et al. 2001) was used to define overstory canopy cover (CC) as a percentage of open sky relative to forest canopy, and effective leaf area index (LAI) integrated over the zenith angles $0^{\circ}$ to $60^{\circ}$ (Stenburg et al. 1994).

At the same time, understory vegetation surveys were carried out in a circular plot of $30 \mathrm{~m}$ radius $\left(2,800 \mathrm{~m}^{2}\right)$ centered in each sampling site, where vascular plants (Dicotyledonae, 
Monocotyledonae and Pteridophyta) were identified to the species level, following Moore (1983) and Correa (19691998). Afterwards, forest floor and vegetation cover estimations were conducted, considering each vascular plant species separately and non-vascular plants (mosses and liverworts) together as a group (Pauchard et al. 2000). Also, debris cover (woody material up to $3 \mathrm{~cm}$ diameter) and bare soil without vegetation (including litter) were estimated. Species richness was calculated as the total number of vascular plant species identified in each sampling site and per habitat type (forest type and crown cover classes). For some analyses, vascular plant species were grouped as follows: saplings (trees less than $1 \mathrm{~m}$ in height), shrubs, other dicots, monocots, and ferns.

\section{Characterization of forest avifauna}

Bird assemblages at each study site were described using (i) point counts (Lencinas et al. 2005, 2009), (ii) checklists of all birds seen during field work, and (iii) mist-netting (Ippi et al. 2009), which are three complementary approaches to more fully describe the species composition of forest birds in Tierra del Fuego (Anderson and Rozzi 2000). Point counts were done for each habitat type at the beginning of each season (October, January, April and July for spring, summer, autumn and winter, respectively). Surveys were conducted in a 4-h period following sunrise, and work was conducted under similar climatic conditions, discarding foggy, windy or rainy days. To determine the bird community assemblage at the forest stand level, we used a point count method with unlimited distances, developed specifically for studies in Tierra del Fuego (see Deferrari et al. 2001, Lencinas et al. 2005, 2009). Points were visited four times each season, reaching a total of 192 counts. Each field observer took an equal number of samples, and the sampling point order was changed daily to balance the effect of time at the day on observations (Shields 1977). Each point count consisted of a 2-minute period for habituation and an effective counting period of 8-minutes. Sampling included direct sighting with binoculars, and calls were used to visually locate individuals. Point counts are known to have methodological deficiencies when there are cryptic species or when the habitat inhibits observation (e.g., noise, dense foliage, etc.). However, this method and the observance times and distances agree with the ranges calculated by Vergara et al. (2010) and Jimenez (2000) for southern Patagonian forests, who also showed that due to low species richness and relatively simple forest structure, bird species detectability was $90 \%$ in observation durations of $<6 \mathrm{~min}$ for these forest types at $<50 \mathrm{~m}$ radius plots. Furthermore, southern Patagonian forest birds are not shy, often coming towards the observer rather than hiding. Observed birds were identified to the species level following Clements (2008) checklist (http://avibase.bsc-eoc.org), and we recorded each individual's habitat use and behavior (on forest soil and/or understory, on tree stems, at overstory canopy level or flying).

To determine avian density, we measured horizontal observation distance $(\mathrm{m})$ between each bird or group of birds and the center of the point, using a TruPulse laser rangefinder (Laser Technology, USA). Density then was calculated us- ing the individuals found within an area that was half of the maximum observation distance from each treatment to account for decreases in detectability with increasing distance (17.0 $\mathrm{m}$ in CL-MDE, $30.0 \mathrm{~m}$ in OP-MDE, $22.5 \mathrm{~m}$ in CL-MD, $35.0 \mathrm{~m}$ in OP-MD, for complete description see Lencinas et al. 2005). Species biomass was determined from the average weight measurements obtained during mist-netting and was completed using literature data for species not caught during banding (Humphrey et al. 1970, Morgado et al. 1987, Sabat 2000, Anderson et al. 2002).

Checklists of all birds seen during field work, including samplings and incidental observations, were used to determine species richness in each forest treatment type. For mistnetting, seven mist-nets $(6-12 \mathrm{~m}$ in length, totaling $66 \mathrm{~m}, \times$ $2.6 \mathrm{~m}$ in height and with $3 \mathrm{~cm} \times 3 \mathrm{~cm}$ mesh) were deployed at fixed locations in the two forest types (MDE and MD). Surveys in each forest type were conducted during 3 days (12 $\mathrm{h}$ capture) at the beginning of three different seasons (spring, summer and autumn). Each day, mist-nets were opened after sunrise and closed before mid-day. Each captured bird was banded with a uniquely numbered ring to avoid repeating measurements. Weight (g), length of extended wing ( $\mathrm{mm})$, beak culmen length to the feathers $(\mathrm{mm})$ and tarsus $(\mathrm{mm})$ were recorded for each individual for biometric characterization. Finally, bird species were classified by their trophic position, using feeding guilds as a proxy according to available bibliography (Humphrey et al. 1970, Narosky and Yzurieta 1987): carnivore (CAR), insectivore (INS) and herbivore (HER). Omnivorous birds were distributed equally between INS and HER. Finally, the capture rate of birds in mist-nets was calculated as the total number of birds captured divided by the total effort ( $\mathrm{m}^{-1}$ of net used $\times$ the $\mathrm{h}$ net open) per forest type per season.

\section{Statistical analyses}

The following statistical analyses were done: (i) two-way ANOVAs of forest structure (DH, D, QMD, BA, CC, LAI) and understory cover variables, using forest type (MDE, MD) and canopy cover (CL, OP) as main factors; (ii) three-way ANOVAs of bird community structure (richness, density) and function (biomass) using forest type (MDE, MD), canopy cover (CL, OP) and season (spring, summer, fall, winter) as main factors; (iii) detrended correspondence analysis (DCA), using point-count censuses to compare bird communities (species richness, density) between forest types; (iv) DCA, using understory plant cover surveys to compare plant communities (species richness, coverage) between forest types (see Lee and Rotenberry 2005); (v) canonical correspondence analysis (CCA) (ter Braak and Šmilauer 2002), using bird point-count censes and forest structure and understory cover variables to estimate the drivers of variance in avian communities between forest types. A post-hoc Tukey's test, corrected for unequal $\mathrm{N}$, was used for all mean comparisons $(\mathrm{p}<0.05)$. 
Table 1. Forest structure and floor cover in Fuegian Nothofagus forests were compared between forest types (MD, MDE) and canopy covers (CL, OP) in two-way ANOVAs. The following variables were measured in overstory trees: NA: BA of Nothofagus antarctica, NP: BA of N. pumilio, NB: BA of N. betuloides, and DW: BA of Drimys winteri.

\begin{tabular}{|c|c|c|c|c|c|c|c|}
\hline \multirow{2}{*}{ Variable } & \multicolumn{3}{|c|}{ Forest type } & \multicolumn{3}{|c|}{ Canopy cover } & \multirow{2}{*}{$\begin{array}{c}\text { Interactions } \\
\mathrm{F}(\mathrm{p}) \\
\end{array}$} \\
\hline & $\mathrm{MD}$ & MDE & $\mathrm{F}(\mathrm{p})$ & $\mathrm{CL}$ & $\mathrm{OP}$ & $\mathrm{F}(\mathrm{p})$ & \\
\hline DH (m) & $6.4 \mathrm{a}$ & $11.3 \mathrm{~b}$ & $27.09(0.001)$ & $12.4 \mathrm{~b}$ & $5.3 \mathrm{a}$ & $58.74(<0.001)$ & $23.85(0.001)$ \\
\hline QMD (cm) & $8.2 \mathrm{a}$ & $23.9 \mathrm{~b}$ & $41.14(<0.001)$ & $24.4 \mathrm{~b}$ & $7.8 \mathrm{a}$ & $45.84(<0.001)$ & $38.56(<0.001)$ \\
\hline D (\# ha-1) & $3694 \mathrm{~b}$ & $323 \mathrm{a}$ & $20.12(0.002)$ & $3216 \mathrm{~b}$ & 801 a & $10.33(0.01)$ & $10.69(0.01)$ \\
\hline CC (\%) & 59.5 & 62.6 & $1.32(0.28)$ & $83.9 \mathrm{~b}$ & $38.1 \mathrm{a}$ & $293.15(<0.001)$ & $4.27(0.07)$ \\
\hline LAI & $1.02 \mathrm{a}$ & $1.41 \mathrm{~b}$ & $6.97(0.03)$ & $2.23 \mathrm{~b}$ & $0.19 \mathrm{a}$ & $189.45(<0.001)$ & $6.51(0.034)$ \\
\hline $\mathrm{BA}(\mathrm{m} 2$ ha-1) & 22.7 & 15.6 & $1.37(0.23)$ & $34.6 \mathrm{~b}$ & $3.7 \mathrm{a}$ & $32.89(0.001)$ & $0.20(0.67)$ \\
\hline NA (m ha-1) & $21.0 \mathrm{~b}$ & $1.3 \mathrm{a}$ & $31.29(0.001)$ & $19.0 \mathrm{~b}$ & $3.3 \mathrm{a}$ & $19.86(0.002)$ & $19.86(0.002)$ \\
\hline $\mathrm{NP}$ (m2 ha-1) & 1.7 & 6.9 & $3.28(0.11)$ & $8.3 \mathrm{~b}$ & $0.3 \mathrm{a}$ & $7.46(0.03)$ & $4.17(0.08)$ \\
\hline NB (m2 ha-1) & 0.0 & 5.0 & $4.69(0.06)$ & 5.0 & 0.0 & $4.69(0.06)$ & $4.69(0.06)$ \\
\hline DW (m2 ha-1) & 0.0 & 2.3 & $1.58(0.24)$ & 2.3 & 0.0 & $1.58(0.24)$ & $1.58(0.24)$ \\
\hline Saplings (\%) & $0.7 \mathrm{a}$ & $4.1 \mathrm{~b}$ & $5.50(0.05)$ & 3.3 & 1.5 & $1.53(0.25)$ & $1.47(0.26)$ \\
\hline Shrubs (\%) & $28.9 \mathrm{~b}$ & $9.3 \mathrm{a}$ & $10.94(0.011)$ & $8.5 \mathrm{a}$ & $29.6 \mathrm{~b}$ & $12.60(0.01)$ & $0.77(0.41)$ \\
\hline Other dicots $(\%)$ & 26.0 & 27.6 & $0.04(0.84)$ & 27.4 & 26.2 & $0.02(0.90)$ & $0.01(0.98)$ \\
\hline Monocots (\%) & $2.2 \mathrm{a}$ & $17.1 \mathrm{~b}$ & $138.20(<0.001)$ & $1.3 \mathrm{a}$ & $18.0 \mathrm{~b}$ & $173.48(<0.001)$ & $111.31(<0.001)$ \\
\hline Ferns (\%) & 7.2 & 17.4 & $2.95(0.12)$ & 13.5 & 11.0 & $0.18(0.68)$ & $0.02(0.89)$ \\
\hline Non-vascular plants (\%) & 11.7 & 2.8 & $3.92(0.03)$ & 4.3 & 10.2 & $1.71(0.23)$ & $0.62(0.46)$ \\
\hline Debris (\%) & 5.8 & 9.2 & $0.44(0.52)$ & $14.2 \mathrm{~b}$ & $0.8 \mathrm{a}$ & $7.11(0.03)$ & $0.11(0.75)$ \\
\hline Bare soil (\%) & 17.7 & 12.5 & $0.86(0.38)$ & $27.5 \mathrm{~b}$ & $2.6 \mathrm{a}$ & $19.98(0.002)$ & $0.01(0.98)$ \\
\hline
\end{tabular}

$\mathrm{F}=$ Fisher test; $(\mathrm{p})=$ probability. Letters in each line indicate differences using Tukey test $(\mathrm{p}<0.05)$.

\section{Results}

\section{Forest structure and plant community characterization}

Forest structure significantly changed with forest type and canopy cover classes (Table 1). In MDE sites, DH, QMD and LAI of the overstory were significantly higher than in MD sites, while D and BA of $N$. antarctica trees were significantly higher in MD than in MDE. CC in CL was significantly higher than in OP sites. Also, forest floor cover significantly changed with forest type and CC classes (Table 1). With regards to forest type, sapling and monocot cover were significantly higher in MDE than in MD, and shrub cover was significantly higher in MD than in MDE. Meanwhile, within a habitat, shrub and monocot cover were significantly higher in OP than in CL sites, and debris cover and bare soil were significantly higher in CL than in OP areas.

\section{Bird captures}

A total of 111 birds were captured (52 in MDE and 59 in MD) during mist-netting (Table 2) with $15 \%$ in spring, $63 \%$ in summer and $22 \%$ in autumn. The capture rate generally was similar between habitat types. For example, spring levels $\left(0.013\right.$ and 0.012 individuals $\mathrm{m}^{-1} \mathrm{~h}^{-1}$ for MDE and MD, respectively) and autumn levels ( 0.016 and 0.015 individuals $\mathrm{m}^{-1} \mathrm{~h}^{-1}$ for MDE and MD, respectively) were similar between both the habitats and the seasons, but summer capture rates were both higher and more varied between habitats $(0.038$ and 0.062 individuals $\mathrm{m}^{-1} \mathrm{~h}^{-1}$ for MDE and MD, respectively).

The mist-nets that were employed allowed the capture of 11 species of small (e.g., Tufted Tit-Tyrant with 6.4 gr weight, $51.3 \mathrm{~mm}$ wing, $8.3 \mathrm{~mm}$ beak and $19.7 \mathrm{~mm}$ tarsus) to medium-sized birds (e.g., Austral Blackbird with 136.0 gr weight, $135.2 \mathrm{~mm}$ wing, $33.1 \mathrm{~mm}$ beak and $41.0 \mathrm{~mm}$ tarsus) (Table 2).

\section{Bird richness and density}

A total of 24 bird species were observed in the studied forests: MDE-CL was the most diverse habitat with 20 species, 4 of which were exclusively found in this forest type. MD-OP was the second most diverse habitat, with 18 species, while MDE-OP had 17 species (2 exclusive species) and MD$\mathrm{CL}$ had 15 species. All the bird species detected in MD stands were also observed in the MDE stands (Appendix 1). Average annual avian densities varied for bird species and habitat type (CL or OP). Some species presented very low overall densities; few individuals were captured, sampled or detected during the entire field study (e.g., birds of prey like the Bicolored Hawk (Accipiter bicolor) or Austral Pygmy Owl (Glaucidium nanum) with $<0.01$ ind. ha-1). However, other species were very abundant and easy to capture at all times of the year 
Table 2. Biometric values of bird species (mean \pm S.D.) inhabiting Fuegian Nothofagus forests that were caught during mist-netting. See species codes in Appendix 1.

\begin{tabular}{lrrrrr}
\hline Species & $\mathrm{n}$ & Weight $(\mathrm{g})$ & Wing $(\mathrm{mm})$ & Beak $(\mathrm{mm})$ & Tarsus $(\mathrm{mm})$ \\
\hline ANPA & 4 & $6.4 \pm 0.7$ & $51.3 \pm 3.9$ & $8.3 \pm 1.9$ & $19.7 \pm 0.9$ \\
SESE & 3 & $6.5 \pm 0.7$ & $61.0 \pm 1.0$ & $17.9 \pm 2.1$ & $6.7 \pm 0.6$ \\
TRAE & 32 & $11.2 \pm 0.7$ & $53.0 \pm 3.2$ & $10.0 \pm 1.0$ & $19.6 \pm 1.4$ \\
APSP & 35 & $12.3 \pm 2.1$ & $59.4 \pm 2.9$ & $9.9 \pm 0.9$ & $21.4 \pm 1.6$ \\
SCMA & 1 & 14.3 & 54.0 & 8.5 & 19.4 \\
TAME & 4 & $16.5 \pm 1.1$ & $111.3 \pm 7.0$ & $7.7 \pm 2.1$ & $13.5 \pm 0.8$ \\
ELAL & 11 & $16.5 \pm 1.7$ & $77.1 \pm 4.5$ & $9.0 \pm 0.5$ & $20.7 \pm 1.8$ \\
PHPA & 4 & $23.0 \pm 2.0$ & $78.3 \pm 1.7$ & $15.2 \pm 4.8$ & $22.4 \pm 8.3$ \\
ZOCA & 10 & $23.1 \pm 1.6$ & $79.6 \pm+3.0$ & $10.3 \pm 1.3$ & $23.3 \pm 1.4$ \\
TUFA & 6 & $90.6 \pm 4.5$ & $137.3 \pm 6.3$ & $21.0 \pm 0.8$ & $42.8 \pm 1.7$ \\
CUCU & 1 & 136.0 & 135.2 & 33.1 & 41.0 \\
\hline
\end{tabular}

Table 3. Bird richness and density in Fuegian Nothofagus forests was compared between forest type (MD, MDE), canopy cover (CL, $\mathrm{OP})$ and season with three-way ANOVAs.

\begin{tabular}{llrr}
\hline Factor & Treatment & Richness (spp. plot-1) & Density (ind. ha-1) \\
\hline A: Forest type & MD & $2.0 \mathrm{a}$ & $21.2 \mathrm{~b}$ \\
& MDE & $2.9 \mathrm{~b}$ & $15.2 \mathrm{a}$ \\
\cline { 2 - 4 } & $\mathrm{F}(\mathrm{p})$ & $17.55(<0.001)$ & $4.34(0.04)$ \\
\hline \multirow{2}{*}{ B: Canopy cover } & OP & $2.9 \mathrm{~b}$ & $12.4 \mathrm{a}$ \\
& $\mathrm{CL}$ & $2.0 \mathrm{a}$ & $24.1 \mathrm{~b}$ \\
\cline { 2 - 4 } C: Season & $\mathrm{F}(\mathrm{p})$ & $21.06(<0.001)$ & $16.78(<0.001)$ \\
& Spring & $3.2 \mathrm{~b}$ & $19.2 \mathrm{~b}$ \\
& Summer & $3.4 \mathrm{~b}$ & $26.7 \mathrm{~b}$ \\
& Autumn & $1.9 \mathrm{a}$ & $20.1 \mathrm{~b}$ \\
& Winter & $1.2 \mathrm{a}$ & $7.0 \mathrm{a}$ \\
\cline { 2 - 4 } & $\mathrm{F}(\mathrm{p})$ & $23.17(<0.001)$ & $8.22(<0.001)$ \\
\hline Interactions & AxB & $6.38(0.01)$ & $0.03(0.86)$ \\
& AxC & $2.54(0.06)$ & $1.12(0.34)$ \\
& BxC & $4.94(0.003)$ & $2.14(0.10)$ \\
& AxBxC & $0.36(0.79)$ & $0.30(0.82)$ \\
\hline F = Fisher test; $(\mathrm{p})=$ probability Letters in each column indicate differences &
\end{tabular}

(e.g., Thorn-Tailed Rayadito [Aphrastura spinicauda] with 5.5-12.9 ind. ha-1).

During point-counts, species richness per plot was significantly higher in MDE and OP habitats than in MD and CL areas (Table 3). Furthermore, richness was significantly higher during spring and summer, than during autumn and winter. Some significant forest $\times$ season interactions were detected, as well, with OP patches being more intensively used by birds during the summer and autumn than spring and winter seasons. In contrast with richness patterns, bird density was higher in MD and CL sites (21.2 and 24.1 ind. ha ${ }^{-1}$, respectively) than in MDE and OP areas (15.2 and 12.4 ind. ha-1, respectively) (Table 3 ), and as expected, density significantly varied among seasons, increasing from spring (19.2 ha-1) to summer $\left(26.7 \mathrm{ha}^{-1}\right)$, and then decreasing in autumn $(20.1$ $\left.\mathrm{ha}^{-1}\right)$, reaching its minimum during winter $\left(7.0 \mathrm{ha}^{-1}\right)$.

No significant differences were detected in bird biomass as a function of trophic level between forest types and CC. However, carnivorous bird biomass was higher in OP than in $\mathrm{CL}$, insectivore biomass was higher in MD than in MDE and in CL than in OP, while herbivore biomass was higher in MDE than in MD and in CL than in OP. When seasons were analyzed, carnivore and insectivore biomasses did not present significant differences. On the other hand, significant differences were found for herbivores, whereby they increased from spring to summer ( 531 to $567 \mathrm{~g} \mathrm{ha}^{-1}$ ) and then decreased from autumn to winter ( 275 to $46 \mathrm{~g} \mathrm{ha}^{-1}$ ). Total bird biomass significantly increased from spring to autumn (935 to $1,379 \mathrm{~g}$ $\left.\mathrm{ha}^{-1}\right)$ and then decreased in winter $\left(244 \mathrm{~g} \mathrm{ha}^{-1}\right)$. 
Avian assemblage, habitat use and understory plant communities in different forest types

During point-counts, bird species were found to have different habitat use and behaviors, where species preferred areas according to their feeding requirements and micro-habitat adaptations (Fig. 1). Some species were only observed in flight (e.g., Black-chested Buzzard-Eagle [Geranoaetus melanoleucus], Southern Caracara [Caracara plancus] and Green-backed Firecrown [Sephanoides sephaniodes]), while others were only seen on the forest floor and/or understory level (e.g., Magellanic Tapaculo [Scytalopus magellanicus]), or mostly on stems, trunks and branches (e.g., Magellanic Woodpecker [Campephilus magellancius]).

However, beyond use of microhabitat substrates and behavior, bird species presented species specific assemblage patterns that varied depending on forest type and canopy cover. DCA showed differential avian community patterns between some habitats (Fig. 2). Total variance for this DCA reached 0.889 , where Axis 1 presented an eigenvalue of 0.282 and Axis 2 an eigenvalue of 0.099 . This analysis showed that Magellanic Woodpecker strongly preferred MD over MDE forests, while Thorn-Tailed Rayadito and Green-backed Firecrown were more associated to MD-CL stands.

Understory plant species also presented specific assemblages that depended on forest type and canopy cover (Fig. 3 ), and in turn these vegetation patterns explained the bird

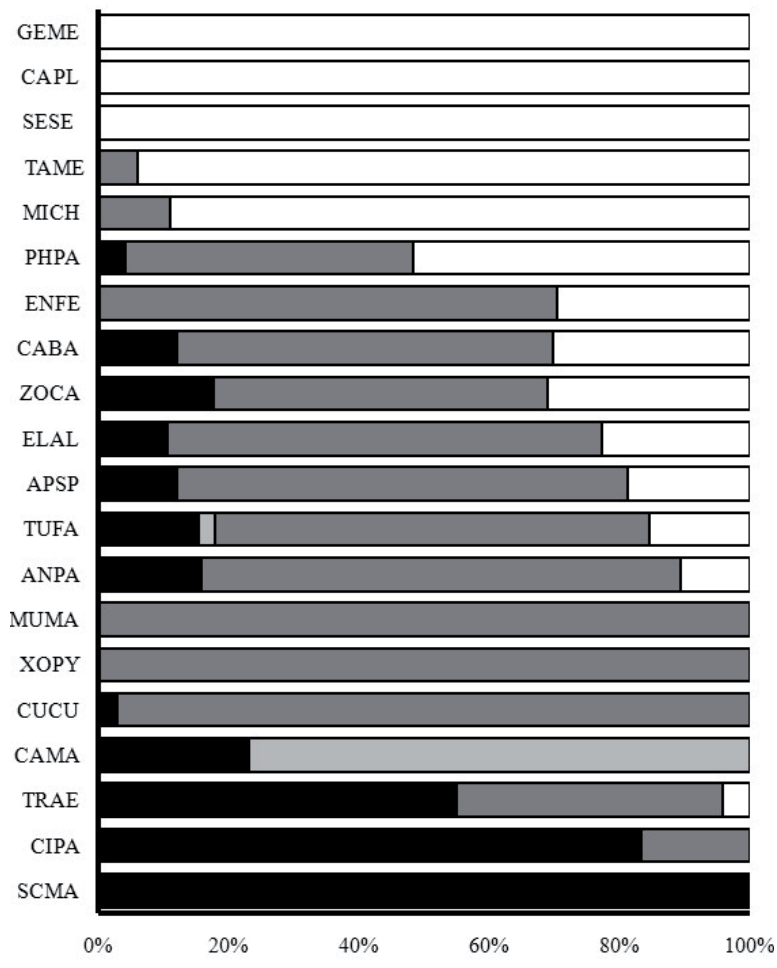

Figure 1. Bird habitat use and behavior observations (\%) in Fuegian Nothofagus forests, classified as: on the forest floor and/ or understory (black), on tree stems (pale grey), at the overstory canopy level (dark grey), or flying (white). See species codes in Appendix 1. preferences for these habitats. Total variance of DCA reached 2.241, where Axis 1 presented an eigenvalue of 0.576 and Axis 2 an eigenvalue of 0.098 . Some characteristic food source plants mostly occurred in one habitat (Appendix 2 and 3), e.g. (i) Pernettya pumila and Empetrum rubrum mostly occurred in open environments of MD, (ii) Berberis buxifolia, Ribes magellanicum and Taraxacum officinale (an exotic species) mostly occurred in MDE-OP, and (iii) Embothrium coccineum mostly occurred in MDE-CL.

Forest structure and floor cover variables (Table 1) partially explained bird species assemblage and differences between forest types. Total CCA variance reached 0.889 , where Axis 1 presented an eigenvalue of 0.215 and Axis 2 an eigenvalue of 0.183 (Fig. 4). Cumulative percentage variance of species-environment relation for Axis 1 and 2 reached $72.8 \%$.

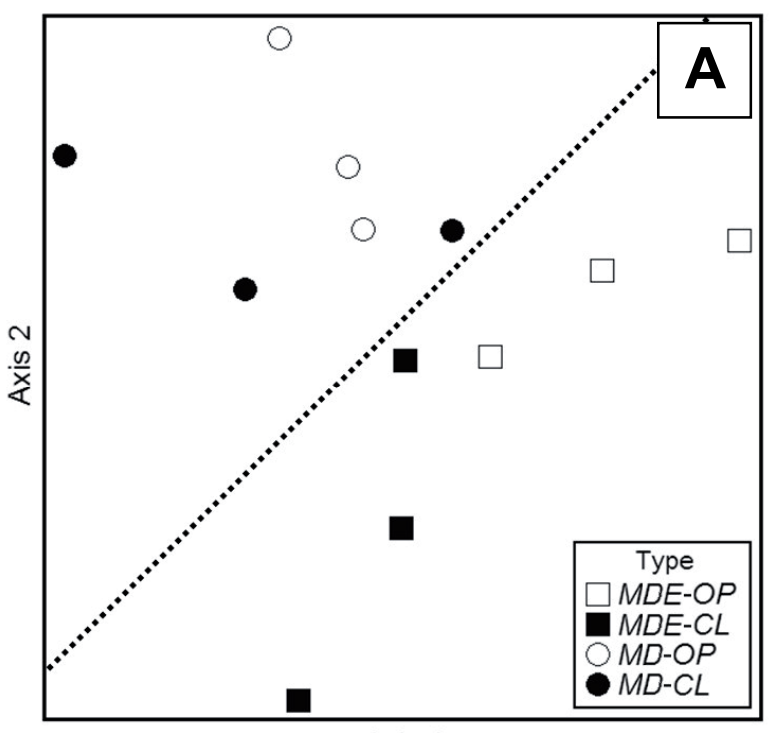

Axis 1

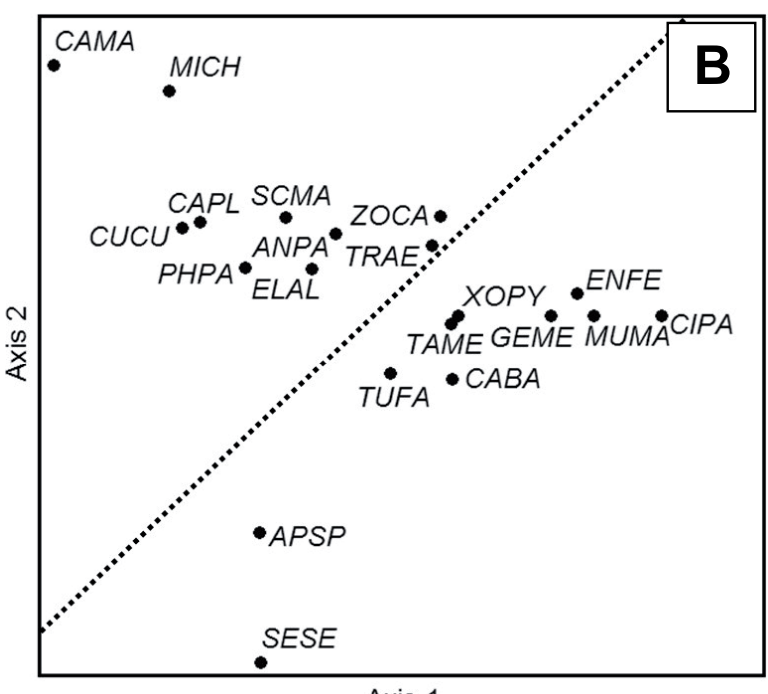

Axis 1

Figure 2. DCA analysis for $(\mathrm{A})$ sampling sites $(\mathrm{MD}=$ mixed of deciduous species, $\mathrm{MDE}=$ mixed of deciduous and evergreen species, $\mathrm{CL}=$ closed, $\mathrm{OP}=$ open), and $(\mathrm{B})$ bird species, based on bird sightings in Fuegian Nothofagus forests. See species codes in Appendix 1. Dotted line separates forest types. 
Table 4. Bird biomass per hectare ( $\left.\mathrm{g} \mathrm{ha}^{-1}\right)$ in Fuegian Nothofagus forests was compared between forest type (MD, MDE), canopy cover (CL, OP) and season with three-way ANOVAs. Biomasses were analyzed as total values and per feeding guild: carnivore (CAR), insectivore (INS) and herbivore (HER). Biomass of omnivorous birds was equally distributed between INS and HER.

\begin{tabular}{llrrrr}
\hline Factor & Treatment & \multicolumn{1}{c}{ CAR } & \multicolumn{1}{c}{ INS } & \multicolumn{1}{c}{ HER } & \multicolumn{1}{c}{ Total } \\
\hline A: Forest type & MD & 156.7 & 446.6 & 275.8 & 879.0 \\
& MDE & 143.1 & 324.8 & 433.7 & 901.7 \\
\cline { 2 - 6 } & F(p) & $0.01(0.91)$ & $0.49(0.48)$ & $1.59(0.21)$ & $0.01(0.93)$ \\
\hline B: Canopy cover & OP & 254.8 & 243.7 & 302.3 & 800.9 \\
& CL & 44.9 & 527.7 & 407.1 & 979.8 \\
\cline { 2 - 6 } C: Season & F(p) & $3.28(0.07)$ & $2.68(0.10)$ & $0.70(0.40)$ & $0.52(0.47)$ \\
& Spring & 28.9 & 374.7 & $531.3 \mathrm{~b}$ & $934.9 \mathrm{ab}$ \\
& Summer & 28.9 & 407.4 & $567.1 \mathrm{~b}$ & $1003.4 \mathrm{ab}$ \\
& Autumn & 409.3 & 694.5 & $274.9 \mathrm{ab}$ & $1378.7 \mathrm{~b}$ \\
& Winter & 132.5 & 66.2 & $45.7 \mathrm{a}$ & $244.4 \mathrm{a}$ \\
\cline { 2 - 6 } Interactions & $\mathrm{F}(\mathrm{p})$ & $2.41(0.07)$ & $2.19(0.09)$ & $3.78(0.01)$ & $3.62(0.01)$ \\
& AxB & $0.43(0.51)$ & $0.06(0.80)$ & $1.33(0.25)$ & $1.13(0.29)$ \\
& AxC & $0.73(0.54)$ & $1.57(0.20)$ & $1.32(0.27)$ & $2.54(0.06)$ \\
& BxC & $0.69(0.56)$ & $0.46(0.71)$ & $1.91(0.13)$ & $0.82(0.49)$ \\
& AxBxC & $0.48(0.69)$ & $0.09(0.97)$ & $1.56(0.20)$ & $0.41(0.75)$ \\
\hline
\end{tabular}

$\mathrm{F}=$ Fisher test; $(\mathrm{p})=$ probability. Letters in each column indicate differences using Tukey test $(\mathrm{p}<0.05)$.

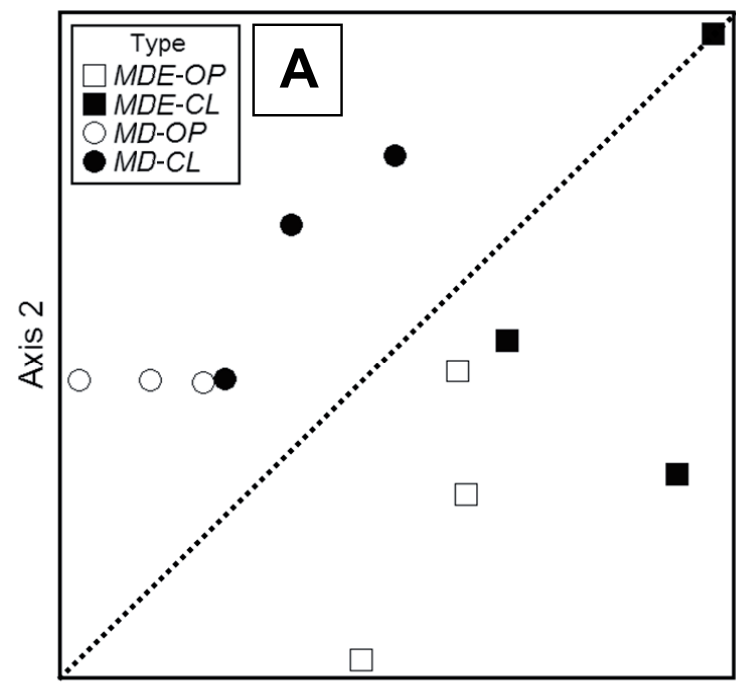

Axis 1

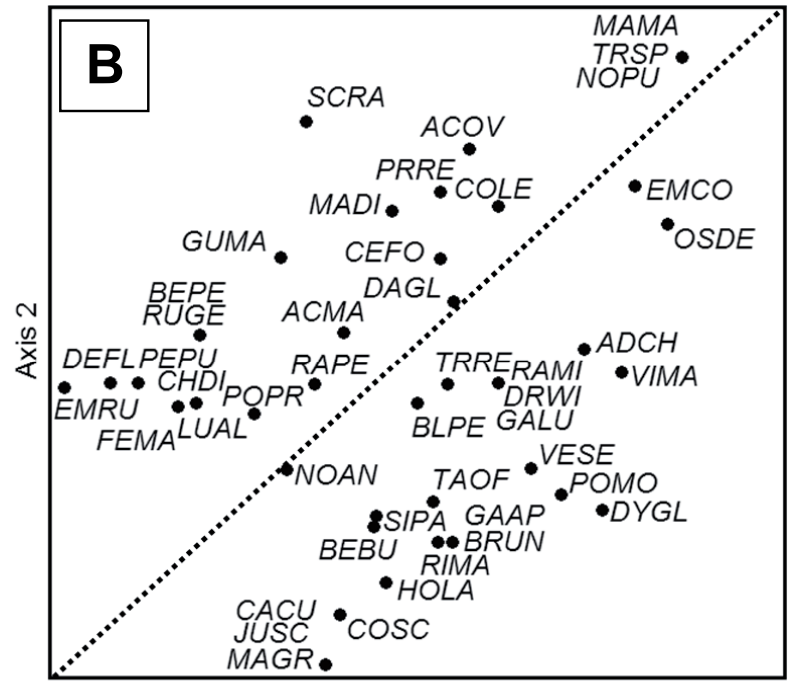

Axis 1

Figure 3. DCA analysis for (A) sampling sites, and (B) vascular plant species, based on understory plant cover in Fuegian Nothofagus forests. See species codes in Appendices 2 and 3. Dotted line separates forest types.

Monocots characterized MDE-OP forests $(F=2.66, p=0.008)$, while shrubs characterized MD-OP forests $(F=1.12$, $p=0.400)$. High QMD $(\mathrm{F}=2.91, \mathrm{p}=0.002)$ and $\mathrm{CC}(F=1.04$, $p=0.384)$ characterized MDE-CL, while high D characterized MD-CL $(F=1.10, p=0.406)$. In the same way, as described in Figs. 2 and 3, bird species presented different specific assemblages related to forest habitat type and floor cover variables. For example, (i) the Dark-faced Ground-Tyrant (Muscisaxicola maclovianus) and the Fire-eyed Diucon (Xolmis pyrope) were mainly related to monocot cover in MDE-OP; (ii) the Tufted Tit-Tyrant was related to shrubs in MD-OP; (iii) the Magellanic
Tapaculo was related to high CC and D in MDE-CL; and (iv) the Magellanic Woodpecker was related to high D in MD-CL.

\section{Discussion}

Habitat drivers of avian community composition in southern Patagonia

Environmental variables, rather than spatial structuring, have been shown to be important drivers of forest bird com- 

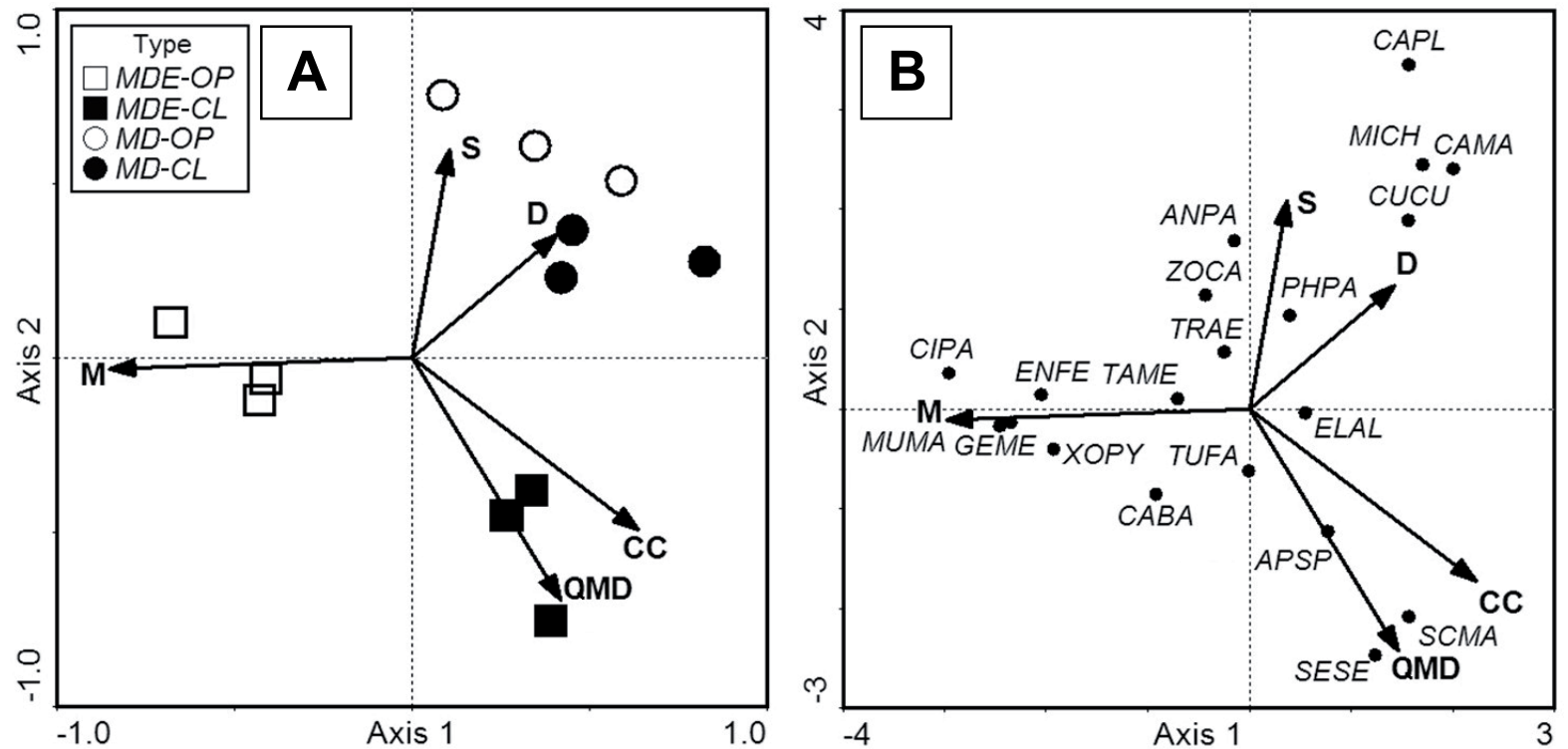

Figure 4. CCA analysis for (A) sampling sites, and (B) bird species, based on bird sightings in Fuegian Nothofagus forests, and using the following explicatory variables: M: monocot species cover (\%), S: shrub species cover (\%), D: density of overstory trees (\#.ha-1), CC: canopy cover of overstory trees (\%), and QMD: quadratic mean diameter of overstory trees (cm). See species codes in Appendix 1.

munity structure in the temperate forests of southern Chile between 34-39 $\mathrm{S}$ (Meynard and Quinn 2008). Ding et al. (2008) showed that where vegetation structure was more heterogeneous (either horizontally or vertically), more types of foraging opportunities existed, and bird species that specialized on specific layers or plant species were more likely to occur. Plus, in a comparative study of forests in Europe, North American and Australia, Kornan et al. (2013) found that similar vegetation structure in these geographically separated systems led to a convergence of guilds in the bird assemblage. In this context, the Fuegian landscape naturally includes a spatially complex mosaic of different forest types and interlaced shrublands, grasslands and peatlands with relatively simple in-habitat physiognomy (Lencinas et al. 2008a). In the case of the studied areas, both habitats were patchy forests with associated non-forested vegetation types, but they also had between habitat variations in stand structure and under- and overstory plant composition that affected food supply and refuge, ultimately affecting bird species richness and composition.

Overall, MDE stands presented larger, less dense trees with a closed canopy. Consequently, these conditions proved to be apt for cavity-nesting bird species like the Magellanic Woodpecker and Austral Parakeet (Enicognathus ferrugineus), as well as for forest dwelling raptors like the Bicolored Hawk and the Austral Pygmy Owl (Lencinas et al. 2005, Ojeda et al. 2007). Additionally, the presence of evergreen trees ( $N$. betuloides, Maytenus magellanica and $D$. winterii) offered more shelter during the colder months (May to October) compared to MD forests, leading to higher abundance and species richness in the winter in these forests. MD forests, on the other hand, were characterized by smaller, denser trees, which were adequate for smaller birds looking for nesting sites in branches or refuge in the dense canopies (e.g., Patagonian Sierra Finch [Phrygilus patagoni- cus]). Also, the MDE forests surveyed in this study had small streams, which are required by certain ground-dwelling forest birds like the Magellanic Tapaculo. In general, the ecological conditions described previously for the MDE forests increased the total species richness in the area; however, the open environments within MDE forests were used mostly by granivorous bird species at the end of summer, when seeds were available. Also, some of these species were only observed in open areas, which increased the average richness for the open habitat treatments compared to forested ones. Yet, overall, avian density in the closed forests was twice that of open areas.

We also were able to determine specific habitat conditions for individual species, such that: (i) forests with large diameter trees and high crown cover (MDE-CL) were positively related to the density of Magellanic Tapaculo and the Greenbacked Firecrown; (ii) lower tree density (OP) was positively related to the density of the Magellanic Woodpecker and some birds of prey (e.g., Chimango Caracara [Milvago chimango] and Southern Caracara); (iii) increased shrub cover was positively related to small bird species, such as Patagonian Tyrant (Colorhamphus parvirostris), as was also described for other Mediterranean bird species (Brotons et al. 2004); and (iv) areas with high grass cover were positively related to characteristics species of grasslands (e.g., Black-faced Ground-Tyrant [Muscisaxicola maclovianus] and Fire-eyed Diucon).

Another important difference between the studied forest types that ultimately drove avian communities was related to their flora composition (Lee and Rotenberry 2005), which could be used by birds as a food supply. For example, while MD had greater overall shrub cover, which can provide habitat required by small, insectivorous species (e.g., Southern House Wren [Troglodytes aedon]), the MDE forests had more shrubs species with palatable fruits (e.g., $R$. magellanicum, $B$. buxifolia) that are needed by the herbivorous feed- 
ing guild. Furthermore, the open habitats within each forest type provided variable understory resources. MDE-OP areas had more exotic seed-bearing plant species, such as Dactylis glomerata, Holcus lanatus, while MD-OP areas displayed fewer alien species and a diminished abundance of seed bearing species. Therefore, as expected, vegetation composition of these habitats affected not only the physical habitat structure, but also other resources. These results coincide with species and micro-habitat requirements for specific feeding guilds, which has also been found in eastern North America from Florida to Nova Scotia (Lee and Rotenberry 2005) and fragmented Mediterranean forests (Brotons et al. 2004).

\section{Southern Patagonian forest avifauna}

Overall, we recorded 24 bird species in this study (see Appendix 1), and the most abundant were Thorn-tailed Rayadito, Patagonian Sierra Finch, White-crested Elaenia (Elaenia albiceps), Austral Thrush (Turdus falcklandii), Chilean Swallow (Tachycineta meyeni) and Southern House Wren, which coincides closely with previous reports on avifauna in the archipelago (Anderson and Rozzi 2000, Ippi et al. 2009). Some species were very scarce; for example, only a few observations were made during the entire study period for species like the Bicolored Hawk, Austral Pygmy Owl, Patagonian Tyrant and White-throated Treerunner (Pygarrhichas albogularis) in MDE forests. A subset of species was only recorded in OP areas (e.g., Dark-bellied Cinclodes (Cinclodes patagonicus), Black-chested BuzzardEagle, Dark-faced Ground-Tyrant) or CL forests (e.g., Magellanic Tapaculo). Yet, the majority of species were found in all the habitats, but displayed important differences regarding the intensity and type of use for species between each habitat type. For instance, the Thorn-tailed Rayadito used all studied areas, but was more abundant in CL forests (5.5-13.0 ind. ha-1) than in OP areas (1.8-2.3 ind. ha-1). In contrast, the Chilean Swallow preferred OP areas (1.1-2.7 ind. ha-1), but was still found to use CL forests (0.7-1.8 ind. ha-1).

The migratory patterns of several species also affected observed seasonal dynamics. For example, the White-crested Elaenia and the Rufous-collared Sparrow (Zonotrichia capensis) were very abundant, but were only present in the breeding season, which coincides with other reports in the area (Lencinas et al. 2005, Brown et al. 2007, Ippi et al. 2009). Previously, Ippi et al. (2009) found that about 33\% of the Fuegian forest bird species was migratory, and our results support this conclusion. One-third, however, is a much lower value than the percentage of migratory species that make up Nothofagus forests farther north $\left(41^{\circ} \mathrm{S}\right)$, where up to $61 \%$ of the species are non-resident (Becerra Serial and Grigera 2005). Instead, the forest avian community in Tierra del Fuego was more similar to tropical forests, such as those of southern Mexico where only $30 \%$ of the species were Neotropical migrants (Estrada and Coates-Estrada 2005).

Furthermore, the biometric values obtained from mistnetting in this study were within the range of data previously reported for the archipelago (e.g., Humprey et al. 1970, Morgado et al. 1987, Sabat 2000, Anderson et al. 2002).
Specifically regarding bird biomass, the avian community of Tierra del Fuego occupies an intermediate level (879.0 $\mathrm{g} \mathrm{ha}^{-1}$ and $901.7 \mathrm{~g} \mathrm{ha}^{-1}$ in MD and MDE, respectively), when compared to other forest ecosystems around the world. For example, Brockie and Moeed (1986) presented bird biomasses from 40 to 3,900 $\mathrm{g} \mathrm{ha}^{-1}$, including for Nothofagus forests in New Zealand (124 $\left.\mathrm{g} \mathrm{ha}^{-1}\right)$ and Fagus forests in Europe (1,300 $\left.\mathrm{g} \mathrm{ha}^{-1}\right)$.

\section{Thinking about the landscape context and regional conservation}

Conserving habitat heterogeneity at local and regional scales is a key process in maintaining bird diversity patterns in many forest ecosystems around the world (Wiens 1989). At the same time, certain habitats may have greater conservation value than others, if specific areas maintain higher levels of biodiversity and contain the same species as adjacent habitats. In this context, it is important to know how the patterns of avian species richness and composition respond both within and between vegetation types (Lindenmayer et al. 2010). Díaz (2006), for example, showed that mixed oak-pine transition zones in Spain increased bird species richness. However, these areas did not significantly increase bird abundance, compared to either pure oak woodlands or pure pine woodlands. Also, the same study determined the strong influence of understory vegetation (species composition, cover and height) in increasing both bird species richness and abundance. In our study, forested and associated non-forested habitats offered varying ecological conditions and advantages for different bird species. Some bird species showed clear preferences for specific habitat types, while others were more generalists. For example, the Magellanic Woodpecker was strongly associated with MD forests, probably due to the fact that dead and decaying trees associated with its food (Cerambicidae larvae) and nest building sites are more common in these forests than in MDE. Another example is the Green-backed Firecrown, which was found only in MDE habitats that had Embothrium coccineum, whose red tubular flower provides abundant nectar. Such species-specific habitat associations have previously been described in these forests for understory plant and insect communities (e.g., Lencinas et al. 2005, 2008a,b), and further illustrate the need to consider the entire landscape in management and conservation initiatives (Gustafsson et al. 2012).

In conclusion, the mosaic of forested and non-forested environments in Tierra del Fuego conformed together a particular assemblage of bird communities, where some habitat types presented higher richness, but others had higher densities. Still other areas had different ratios of bird trophic levels among different seasons. Forest structure variables and understory plant communities both helped to explain bird community dynamics. Additionally, we observed greater variations in bird community parameters between seasons, which can be understood as a differential use by bird species for each habitat type during the year. Therefore, it is not possible to define specific habitats with greater conservation value; each had a particular assemblage of birds. For this reason, it is possible to define habitats preferred by some species, but not 
specific habitats that possess greater or special conservation value for the broader landscape. As a result, it is necessary to ensure a representative design for protected areas and management of forests that encompasses this diversity of floristic compositional and structural features. By understanding the relationship between bird assemblages, individual bird species requirements, and forest flora, it will be possible to better understand how avian communities are likely to change, which species and areas are likely to be impacted more heavily, and where to direct conservation and management activities in natural reserves (Lee and Rotenberry 2005). However, the lack of long-term ornithological studies that explore mechanisms and processes, rather than simply patterns and descriptions in southern South America has previously hindered the identification of relevant aspects of the autecology and community ecology of even the most common species (Brown et al. 2007).

Acknowledgements: The authors gratefully thank the Administración de Parques Nacionales and the staff of Tierra del Fuego National Park. Project APN-1094 supported this research during 2010-2011, and APN has permitted this ongoing study.

\section{References}

Anderson, C.B. and R. Rozzi. 2000. Bird assemblages in the southernmost forests in the world: methodological variations for determining species composition.Anales del Instituto de la Patagonia, Serie Ciencias Naturales 28: 89-100.

Anderson, C.B., R. Rozzi, C. Elphick and S. Mcgehee. 2002. El programa Omora de anillamiento de aves en los bosques Subantárticos: La estandarización del tamaño de anillos apropiados para las aves de la región de Magallanes. Boletín Chileno de Ornitología 9: 2-11.

Battisti, C. 2014. Peninsular patterns in biological diversity: historical arrangement, methodological approaches and causal processes. J. Nat. Hist. 48: 43-44.

Becerra Serial, R. and D. Grigera. 2005. Dinámica estacional del ensamble de aves de un bosque norpatagónico de lenga (Nothofagus pumilio) y su relación con la disponibilidad de sustratos de alimentación. Hornero 20: 131-139.

Bitterlich, W. 1984. The Relascope Idea. Relative Measurements in Forestry. Commonwealth Agricultural Bureaux, London, UK.

Brockie, R.E. and A. Moeed. 1986. Animal biomass in a New Zealand forest compared with other parts of the world. Oecologia 70: 2434.

Brotons, L., S. Herrando and J.L. Martin. 2004. Bird assemblages in forest fragments within Mediterranean mosaics created by wild fires. Landsc. Ecol. 19: 663-675.

Brown, C., C.B. Anderson, S. Ippi, M. Sherriffs, R. Charlin, S. Mcgehee and R. Rozzi. 2007. The autecology of the fío-fío (Elaenia albiceps Lafresnaye and D'Orbigny) in subantarctic forests of the Cape Horn biosphere reserve, Chile. Anales Instituto Patagonia 35: 29-40.

Clements, J.F. 2008. The Clements Checklist of the Birds of the World. Sixth Ed. London, UK.

Correa, M.N. 1969-1998. Flora Patagónica. Colección Científica INTA, Buenos Aires, Argentina.
Deferrari, G., C. Camilion, G. Martínez Pastur and P.L. Peri. 2001. Changes in Nothofagus pumilio forest biodiversity during the forest management cycle: Birds. Biodiv. Conserv. 10: 2093-2108.

Degraaf, R.M., J.B. Hestbeck and M. Yamasaki. 1998. Associations between breeding bird abundance and stand structure in the White Mountains, New Hampshire and Maine, USA. For. Ecol. Manage. 103: 217-233.

Díaz, I., J.J. Armesto, S. Reid, K. Sieving and M.F. Willson. 2005. Linking forest structure and composition: avian diversity in successional forests of Chiloe' Island, Chile. Biol. Conserv. 123: 91-101.

Díaz, L. 2006. Influences of forest type and forest structure on bird communities in oak and pine woodlands in Spain. For. Ecol. Manage. 223: 54-65.

Díaz, S. and T. Kitzberger. 2006. High Nothofagus flower consumption and pollen emptying in the southern South American austral parakeet (Enicognathus ferrugineus). Aust. Ecol. 31: 759-766.

Ding, T., H. Liao and H. Yuan. 2008. Breeding bird community composition in different successional vegetation in the montane coniferous forests zone of Taiwan. For. Ecol. Manage. 255: 20382048.

Estrada, A. and R. Coates-Estrada. 2005. Diversity of Neotropical migratory land-bird species assemblages in forest fragments and man-made vegetation in Los Tuxtlas, Mexico. Biodiv. Conserv. 14: 1719-1734

Frazer, G.W., R.A. Fournier, J.A. Trofymow and R.J. Gall. 2001. A comparison of digital and film fisheye photography for analysis of forest canopy structure and gap light transmission. Agric. For. Meteorol. 109: 249-263.

Gustafsson, L., S. Baker, J. Bauhus, W. Beese, A. Brodie, J. Kouki, D. Lindenmayer, A. Lõhmus, G. Martínez Pastur, C. Messier, M. Neyland, B. Palik, A. Sverdrup-Thygeson, J. Volney, A. Wayne and J. Franklin. 2012. Retention forestry to maintain multifunctional forests: a World perspective. BioScience 62: 633-645.

Humphrey, P., D. Bridge, P. Reynolds and R. Peterson. 1970. Birds of Isla Grande (Tierra del Fuego). Ed. Smithsonian Institution, Washington, USA.

Ippi, S., C.B. Anderson, R. Rozzi and C. Elphick. 2009. Annual variation of abundance and composition in forest bird assemblages on Navarino Island, Cape Horn Biosphere Reserve, Chile. Ornitologia Neotropical 20: 231-245.

Jimenez, J. 2000. Effect of simple size, plot size, and counting time on estimates of avian diversity and abundance in a Chilean rainforest. J. Field Ornithol. 71: 66-87.

Kornan, M., R.T. Holmes, H.F. Recher, P. Adamík and and R. Kropil. 2013. Convergence in foraging guild structure of forest breeding bird assemblages across three continents is related to habitat structure and foraging opportunities. Community Ecol. 14: 89100.

Kreps, G., G. Martínez Pastur and P.L. Peri. 2012. Cambio climático en Patagonia Sur: Escenarios futuros en el manejo de los recursos naturales. Ed. Instituto Nacional de Tecnología Agropecuaria, Buenos Aires, Argentina.

Lee, P.Y. and J.T. Rotenberry. 2005. Relationships between bird species and tree species assemblages in forested habitats of eastern North America. J. Biogeogr. 32: 1139-1150.

Lencinas, M.V., G. Martínez Pastur, M. Medina and C. Busso. 2005. Richness and density of birds in timber Nothofagus pumilio forests and their unproductive associated environments. Biodiv. Conserv. 14: 2299-2320.

Lencinas, M.V., G. Martínez Pastur, P. Rivero and C. Busso. 2008a. Conservation value of timber quality vs. associated non-timber 
quality stands for understory diversity in Nothofagus forests. Biodiv. Conserv. 17: 2579-2597.

Lencinas, M.V., G. Martínez Pastur, C.B. Anderson and C. Busso. $2008 \mathrm{~b}$. The value of timber quality forests for insect conservation on Tierra del Fuego Island compared to associated non-timber quality stands. J. Insect Conserv. 12: 461-475.

Lencinas, M.V., G. Martínez Pastur, E. Gallo and M. Cellini. 2009 Alternative silvicultural practices with variable retention improve bird conservation in managed South Patagonian forests. For. Ecol. Manage. 258: 472-480.

Lindenmayer, D., J.T. Wood, L. McBurney, D. Michael, M. Crane, C. MacGregor and R. Montague-Drake. 2010. Comparing bird species richness and assemblage composition between montane ash eucalypt forest and cool temperate rainforests - an empirical study from Victoria, south-eastern Australia. Emu 110: 109-117.

Luque, S., G. Martínez Pastur, C. Echeverría and M.J. Pacha. 2010. Overview of biodiversity loss in South America: A landscape perspective for sustainable forest management and conservation in temperate forests. In: C. Li, R. Lafortezza and J. Chen (eds), Landscape Ecology and Forest Management: Challenges and Solutions in a Changing Globe. HEP-Springer, Amsterdam, Holland. pp. 352-379.

Martínez Pastur, G., J.M. Cellini, M.V. Lencinas, M. Barrera and P.L. Peri. 2011. Environmental variables influencing regeneration of Nothofagus pumilio in a system with combined aggregated and dispersed retention. For. Ecol. Manage. 261: 178-186.

Massaccesi, G., F. Roig, G. Martínez Pastur and M. Barrera. 2008. Growth patterns of Nothofagus pumilio trees along altitudinal gradients in Tierra del Fuego, Argentina. Trees, Structure and Function 22: 245-255.

Meynard, C.N. and J.F. Quinn. 2008. Bird meta-communities in temperate South American forests: vegetation structure, area and climate effects. Ecology 89: 981-990.

Moore, D. 1983. Flora of Tierra del Fuego. Anthony Nelson, London, UK.

Morgado, E., B. Günther and U. González. 1987. On the allometry of wings. Rev. Chil. Hist. Nat. 60: 71-79.

Narosky, T. and D. Yzurieta. 1987. Guía para la identificación de aves de Argentina y Uruguay. Asociación Ornitológica del Plata, Buenos Aires, Argentina

Ojeda, V., M.L. Suarez and T. Kitzberger. 2007. Crown dieback events as key processes creating cavity habitat for Magellanic woodpeckers. Aust. Ecol. 32: 436-445.

Pressey R.L., M. Cabeza, M.E. Watts, R.M. Cowling and K.A. Wilson. 2007. Conservation planning in a changing world. TREE 22: $583-592$

Pauchard, A., E. Ugarte and J. Millán. 2000. A multiscale method for assessing vegetation baseline of Environmental Impact Assessment (EIA) in protected areas of Chile. In: S.F. McCool, D.N. Cole, W.T. Borrie and J. O'Loughlin (eds), Wilderness
Science in a time of Change Conference. USDA Forest Service, Rocky Mountain Research Station, USA. pp. 111-116.

Robison, S.A. and C.B. McCarthy. 1999. Potential factors affecting the estimation of light availability using hemispherical photography in oak forest understories. Bull. Torrey Bot. Club 126: 344-349.

Sabat, P. 2000. Intestinal disaccharidases and aminopeptidase-N in two species of Cinclodes (Passerine: Furnaridae). Rev. Chil. Hist. Nat. 73: 345-350.

Shields, W.M. 1977. The effect of time of day on avian census results. The Auk 94: 380-383

Stenburg, P., S. Linder, H. Smolander and J. Flower-Ellis J. 1994. Performance of the LAI-2000 plant canopy analyzer in estimating leaf area index of some Scots pine stands. Tree Physiol. 14: 981-995.

ter Braak, C. and P. Šmilauer. 2002. CANOCO reference manual and CanoDraw for Windows User's guide: software for canonical community ordination. Version 4.5. Microcomputer Power, New York, USA.

Vergara, P. and R. Schlatter. 2006. Aggregate retention in two Tierra del Fuego Nothofagus forests: Short-term effect on bird abundance. For. Ecol. Manage. 225: 213-224.

Vergara, P.M., J.E. Jimenez and R. Schlatter. 2010. Effective pointcount duration for estimating bird species' richness in Chilean forests. Zool. Stud. 49: 381-391.

Vuilleumier, F. 1985. Forest birds of Patagonia: ecological geography, speciation, endemism, and faunal history. Ornithol. Monogr. 36: 255-304.

Wiens, J.A. 1989. The Ecology of Bird Communities. Vol. 1, 2 Cambridge studies in ecology, Cambridge University Press, Cambridge, UK

Received June 13, 2014

Revised August 14, September 19, 2014 Accepted September 24, 2014

\section{Electronic supplement}

Appendix 1. Annual bird species density (ind. ha-1) and relative contribution (\%) to total abundance per forest type in the studied Nothofagus forests, located in the Tierra del Fuego Archipelago.

Appendix 2. Mean ( \pm S.D.) cover of dicotyledonous plant (\%) during summer season in the studied Nothofagus forests of Tierra del Fuego.

Appendix 3. Mean ( \pm S.D.) cover of monocotyledonous plant and fern species (\%) during summer season in the studied Nothofagus forests of Tierra del Fuego.

The file may be downloaded from www.akademiai.com. 